\title{
EF-Hand Domain
}

National Cancer Institute

\section{Source}

National Cancer Institute. EF-Hand Domain. NCI Thesaurus. Code C13956.

Forming a single Ca2+-binding site in many calcium-binding proteins, the basic EF-Hand Domain consists of a conserved 12-residue loop region between two perpendicular 1012 residue alpha helices (helix-loop-helix). Ca2+ interacts with loop residues in a pentagonal bipyramidal configuration; each loop residue is important for $\mathrm{Ca} 2+$ coordination. Loop residues 1, 3, 5, 7, 9, and 12 (invariant Glu or Asp) are directly necessary for Ca2+ binding. Amino-acid variations at positions 1, 3, 5, 7, and 9 alter ion affinity. Single or multiple domains cause structural/functional variations. EF-hand Proteins are grouped into either regulatory/signaling or structural/buffering/transport categories. Ca2+ binding to regulatory proteins induces conformational/functional change; $\mathrm{Ca} 2+$ binding to structural proteins seems to provide a $\mathrm{Ca} 2+$ buffer. $(\mathrm{NCl})$ 